\title{
Maxillary Antroliths: A Digital Panoramic-based Study
}

Georges Aoun ${ }^{1}$, Ibrahim Nasseh ${ }^{1}$

1. Oral Medicine and Maxillofacial Radiology, Faculty of Dental Medicine, Lebanese University, Beirut, LBN

Corresponding author: Georges Aoun, dr.georgesaoun@gmail.com

Abstract
Objectives
Maxillary antroliths are calcified masses found within the maxillary sinus. The aim of this study was to
investigate their presence in a sample of Lebanese population by means of digital panoramic radiographs.

Material and methods

In this study, 500 digital panoramic radiographs of Lebanese adult patients ( 281 females and 219 males) with a median age of $47.9 \pm 18.98$ years were included and examined for maxillary antroliths. The statistical analysis of the data found was performed by IBM ${ }^{\circledR}$ SPSS ${ }^{\circledR}$ (IBM, Armonk, NY) version 20.0 for Windows.

Results

The sample investigated presented only three maxillary antroliths (0.6\%). Among these, two were found in female patients and one in male; none of them was bilateral, one on the right side and two on the left side. No statistically significant relationships were observed with patients' gender and age.

Conclusion

Maxillary antroliths are rare entities detected accidentally on panoramic radiographs utilized frequently in dental clinics. In light of their possible association with chronic sinusitis, dentists should have a complete knowledge of their diagnosis.

Categories: Radiology, Dentistry

Keywords: lebanese, maxillary antrolith, panoramic, radiography

Received 01/07/2020

Review began 01/10/2020 Review ended 01/14/2020 Published 01/17/2020

() Copyright 2020

Aoun et al. This is an open access article distributed under the terms of the Creative Commons Attribution License CC-BY 3.0., which permits unrestricted use, distribution, and reproduction in any medium, provided the original author and source are credited.

\section{Introduction}

Maxillary antroliths (MAs) are calcified masses found in the maxillary sinus and result from the deposition of mineral salt around a foreign body (exogenous origin) or stagnant mucus (endogenous origin) [1,2]. Generally asymptomatic, MAs are rare entities detected accidentally on radiographic examinations (panoramic radiographs, computed tomography [CT], cone beam computed tomography [CBCT], etc.) [1-4]. In some cases, clinical symptoms such as facial pain, purulent and/or blood discharge, buccoantral communication, and others may be present [2,5-7]. Moreover, chronic sinusitis may result from infection around MAs $[2,3,7]$. Adversely, other studies suggest that chronic sinusitis can be behind the development of MAs as chronic infection can promote the deposition of mineral salts in the affected region $[2,8]$. Furthermore, MAs have also been found in sinuses infected by Aspergillus fumigatus [3].

Radiographically, MAs are described as faintly to extremely radiopaque masses embedded within the maxillary sinus. They are irregular, well-defined, and of different sizes and forms $[2,3,7]$. Their radiological differential diagnosis may include radiopacities located in the maxillary sinus such as residual root fragments, osteogenic (osteomas) and odotogenic lesions (cementoma), periapical condensing osteitis, and calcified neoplasms [4].

Normally, histology of MAs shows concentrical rings similar to those found in calculi located in different organs of the body covered by a granulation tissue richly vascularized. Chemical analysis of these entities highlights their formation of calcium phosphate, calcium carbonate, calcium oxalate, albumin, magnesium phosphate, organic substance, and water. As for their consistency, it can vary from hard and friable to soft, spongy, or crumbly. Finally, MAs can be of different colors (white, brown, gray, or black) [8].

With the absence of any radiological investigation for MAs in the Lebanese population, the aim of this study was to assess its prevalence in a sample of Lebanese population by means of digital panoramic radiographs. 


\section{Cureus}

\section{Materials And Methods}

In this retrospective study, digital panoramic radiographs of Lebanese adult patients were investigated. These radiographs, originally taken for dental reasons, were obtained from the archive of a radiology center located in Beirut.

According to the center regulation, all patients gave their consent for future anonymous use of their radiographs for research purpose. The radiographs of patients who refused to consent were not added to the research archive.

All panoramic radiographs were obtained using the Pax Zenith digital panoramic unit (Vatech, Korea). The settings of the $x$-ray unit were chosen according to the patient profile (60-90 kV, 6-10 mA) with an exposure time between 10 and 20 seconds.

The exclusion criteria included the absence of patients' information (age and sex) and low-quality images.

Eventually, the sample was composed of 500 panoramic radiographs (219 males and 281 females) with an average age of 47.9 years.

One maxillofacial radiologist having more than 25 years of experience reviewed the radiographs for MAs; he used the same computer monitor and configuration to interpret the total sample.

Data collection took 10 sessions spaced by a 20 -day period.

To avoid errors, 50 radiographs randomly chosen were rechecked 10 days after the first assessment while blinded to the primary results.

MAs were identified as solitary or multiple radiopaque masses embedded within the antrum of the maxillary sinus, most frequently above the floor (Figures 1,2).

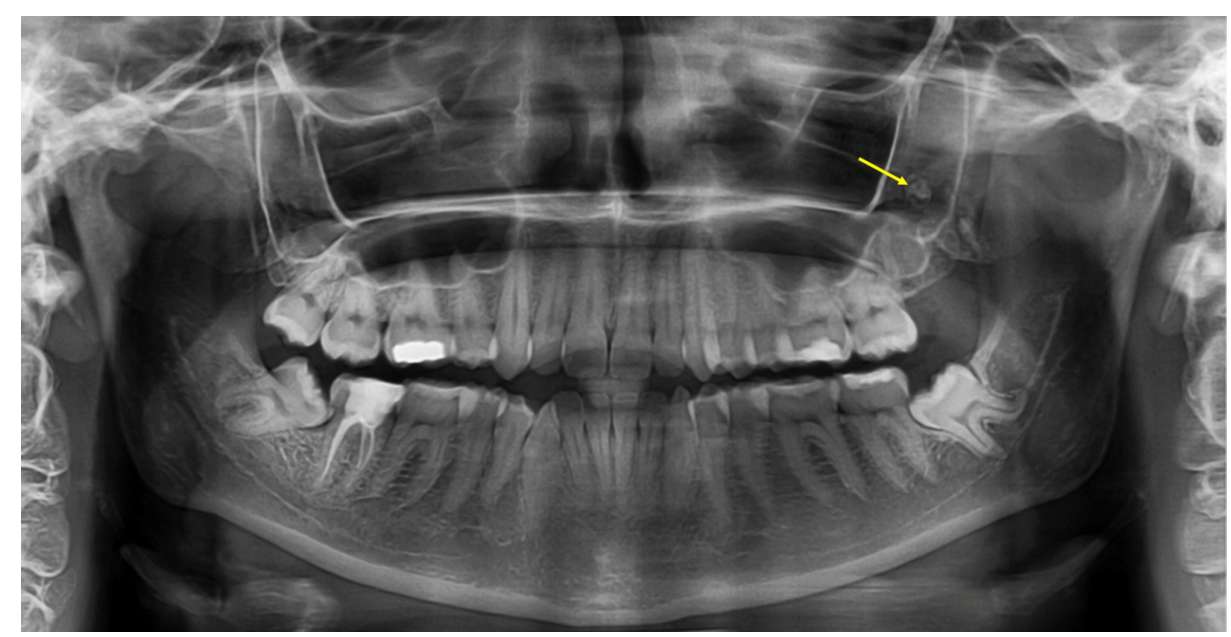

FIGURE 1: Antrolith within the left maxillary sinus

A panoramic radiograph showing the presence of a maxillary antrolith within the left maxillary sinus. 


\section{Cureus}

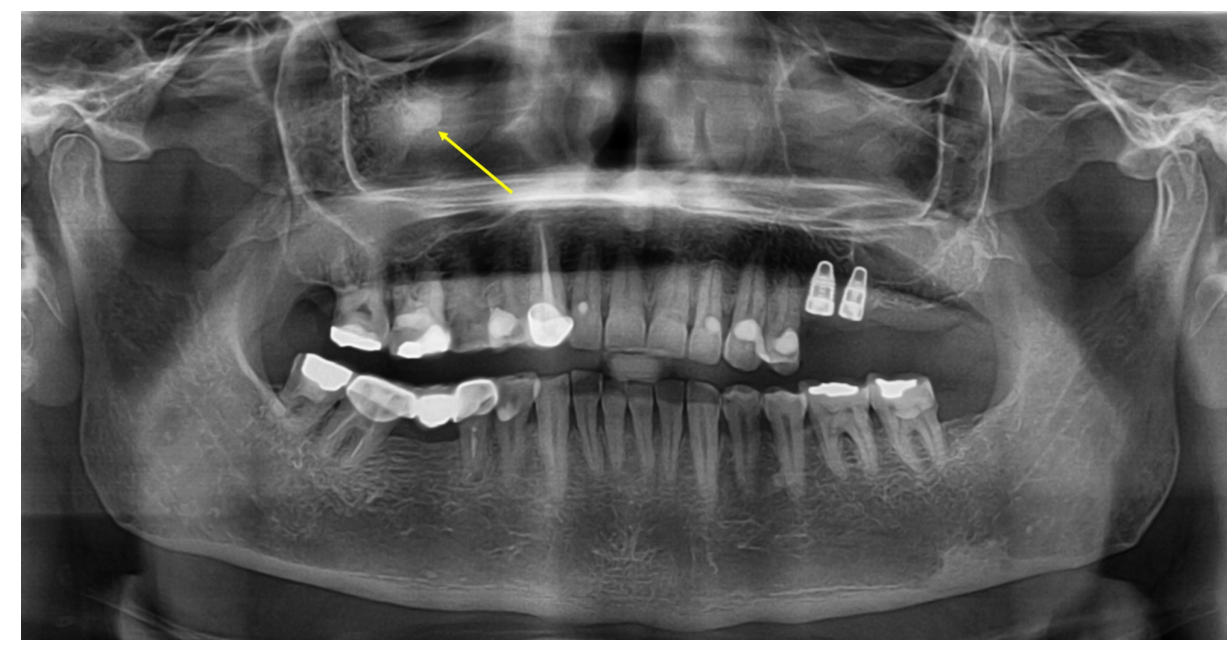

\section{FIGURE 2: Antrolith within the right maxillary sinus}

A panoramic radiograph showing the presence of a maxillary antrolith within the right maxillary sinus.

Statistical analyses were carried out by IBM SPSS for Windows version 20.0 (IBM, Armonk, NY). Descriptive statistics of age, sex, and MAs were calculated and presented as frequency and percentage for categorical variables and as mean \pm standard deviation for continuous ones. Normality was evaluated for all the variables. Fisher's exact test and Spearman correlation analysis were used to test statistical significance. Pvalues $<0.05$ were considered statistically significant.

\section{Results}

In this study, the sample consisted of 500 adult patients (219 males, $43.8 \%$ and 281 females, $56.2 \%$ ) aged 18 88 years (mean: $47.9 \pm 18.98$ years).

MAs were seen in $0.6 \%$ (three cases) of the study population. Among these $0.2 \%$ (one case) was on the right side, $0.4 \%$ (two cases) on the left side (Table 1 ).

\begin{tabular}{|l|l|l|}
\hline & N & Percentage \\
\hline Right side only & 1 & 0.2 \\
Left side only & 2 & 0.4 \\
Bilateral & - & - \\
None & 497 & 99.4 \\
Total & 500 & 100 \\
\hline
\end{tabular}

TABLE 1: Distribution of maxillary antroliths by side

As for the descriptive statistics based on sex, MAs were seen in:

- $0.7 \%$ (two cases) of the female study population, one ( $0.35 \%)$ on each side.

- $0.45 \%$ (one case) of the male study population, on the left side (Table 2). 


\section{Cureus}

\begin{tabular}{|l|l|l|}
\hline & Presence of maxillary antroliths & Percentage \\
\hline Male $(n=219)$ & 1 & 0.45 \\
\hline Female $(n=281)$ & 2 & 0.7 \\
\hline
\end{tabular}

TABLE 2: Distribution of maxillary antroliths by sex

Fisher's exact test revealed insignificant association between gender and MAs $(p=1>0.05)$.

The mean age for patients affected by MAs was 40.6 years (ranges from 23 to 53 years). Spearman correlation analysis showed a non-significant, very weak negative correlation between age and MAs $(\mathrm{p}=0.499>0.05)$.

These statistical results were expected due to the small number of cases obtained in this study.

\section{Discussion}

MAs are calcifications that form within the maxillary sinus as a consequence of mineral salt deposition around an exogenous (piece of cotton, dental implants, gutta-percha cones, etc.) or endogenous (tooth, osseous fragments, mucus, etc.) nucleus [3,9-14]. This formation process is not yet clear, but chronic infections (bacterial and fungal), reduced sinus drainage, and the existence of foreign bodies are risk factors $[9,11]$.

Panoramic radiography is frequently requested by dentists in daily practice. It provides essential information that is difficult to obtain from clinical assessment such as horizontal alveolar bone loss, dental impaction patterns, periapical lesions, and dentoalveolar fractures [15]. Additionally, it is known to be an effective technique in the detection of some maxillary sinus pathologies.

In the present study, we investigated MAs in a sample of adult Lebanese patients by means of digital panoramic radiographs. In the literature, a very small number of studies explored MAs using this radiological technique; the majority used $\mathrm{CBCT}$ in their MAs assessment.

In our study, the prevalence of MAs was $0.6 \%$ (three cases out of 500 images reviewed). Interestingly, in their study, Nass Duce et al. found the same number of cases (three) but in a larger sample $(1,957$ radiographs) taken originally with a different imaging technique (paranasal sinus CT); their incidence of MAs was $0.15 \%[16]$.

On the other hand, other studies reported slightly higher occurrences of MAs than ours (Cho et al. 0.99\%, $\mathrm{N}=13,946$, СBCT technique; Lana et al. 3.2\%, N=500, CBCT technique; Rege et al. $3.2 \%, \mathrm{~N}=1,113$, CBCT technique) $[1,17,18]$. This small variation existing between all these studies and ours might be related to the assessed images. In fact, because of the anatomic structures superimpositions caused by the twodimensional radiography, panoramic technique could miss small MAs. In contrast, CT and CBCT can undoubtedly detect MAs independent of their size and shape. However, the cost and the high radiation dosage of CT limit its use in favor of 2D and CBCT techniques, which can offer helpful information on MAs without high radiation exposure [19].

Finally, our study aiming to estimate the incidence of MAs in an adult Lebanese population is not without limitations. A bigger sample and the evaluation on 3D images can, definitely, lead to more precise results.

\section{Conclusions}

MAs are rare calcifications located within the maxillary sinus. In daily dental practice, they could be accidentally discovered on digital panoramic radiographs taken for diagnostic purposes. Dentists should be aware about these entities in order to prevent subsequent complications mainly chronic sinusitis.

\section{Additional Information \\ Disclosures}

Human subjects: All authors have confirmed that this study did not involve human participants or tissue. Animal subjects: All authors have confirmed that this study did not involve animal subjects or tissue. Conflicts of interest: In compliance with the ICMJE uniform disclosure form, all authors declare the following: Payment/services info: All authors have declared that no financial support was received from any organization for the submitted work. Financial relationships: All authors have declared that they have no financial relationships at present or within the previous three years with any organizations that might 
have an interest in the submitted work. Other relationships: All authors have declared that there are no other relationships or activities that could appear to have influenced the submitted work.

\section{References}

1. Cho BH, Jung YH, Hwang JJ: Maxillary antroliths detected by cone-beam computed tomography in an adult dental population. Imaging Sci Dent. 2019, 49:59-63. 10.5624/isd.2019.49.1.59

2. Manning N, Wu P, Preis J, Ojeda-Martinez H, Chan M: Chronic sinusitis-associated antrolith. IDCases. 2018, 14:e00467. 10.1016/j.idcr.2018.e00467

3. Shenoy V, Maller V, Maller V: Maxillary antrolith: a rare cause of the recurrent sinusitis . Case Rep Otolaryngol. 2013, 2013:527152. 10.1155/2013/527152

4. Barros CA, Martins RR, Silva JB, e al.: Rhinolith: a radiographic finding in a dental clinic . Oral Surg Oral Med Oral Pathol Oral Radiol Endod. 2005, 100:486-490. 10.1016/j.tripleo.2005.02.073

5. Duce MN, Talas DU, Özer C, Yildiz A, Apaydin FD, Özgür A: Antrolithiasis: a retrospective study. J Laryngol Otol. 2003, 117:637-640. 10.1258/002221503768199997

6. Blaschke DD, Brady FA: The maxillary antrolith. Oral Surg Oral Med Oral Pathol. 1979, 48:187-189. 10.1016/0030-4220(79)90059-8

7. Sugiura T, Yamamoto K, Nakashima C, et al.: Chronic maxillary sinusitis caused by denture lining material . Open Dent J. 2016, 10:261-267. 10.2174/1874210601610010261

8. Nair S, James E, Dutta A, Goyal S: Antrolith in the maxillary sinus: an unusual complication of endoscopic sinus surgery. Indian J Otolaryngol Head Neck Surg. 2010, 62:81-83. 10.1007/s12070-010-0013-9

9. Nass Duce M, Talas DU, Ozer C, Yildiz A, Apaydin FD, Ozgür A: Antrolithiasis: a retrospective study. J Laryngol Otol. 2003, 117:637-640. 10.1258/002221503768199997

10. Güneri P, Kaya A, Calişkan MK: Antroliths: survey of the literature and report of a case . Oral Surg Oral Med Oral Pathol Oral Radiol Endod. 2005, 99:517-521.10.1016/j.tripleo.2004.07.021

11. Wu CW, Tai CF, Wang LF, Tsai KB, Kuo WR: Aspergillosis: a nidus of maxillary antrolith . Am J Otolaryngol. 2005, 26:426-429. 10.1016/j.amjoto.2005.05.009

12. Evans J: Maxillary antrolith: a case report. Br J Oral Surg. 1975, 13:73-77. 10.1016/0007-117x(75)90025-6

13. Minkow B, Laufer D, Gutman D: Acute maxillary sinusitis caused by a guttapercha point . Refuat Hapeh Vehashinayim. 1977, 26:33-34.

14. Ogata Y, Okinaka Y, Takahashi M: Antrolith associated with aspergillosis of the maxillary sinus: report of a case. J Oral Maxillofac Surg. 1997, 55:1339-1341. 10.1016/s0278-2391(97)90198-1

15. White SC, Pharoa MJ: Oral Radiology: Principles and Interpretation, 5th ed. Mosby, St. Louis; 2004.

16. Nass Duce M, Talas DU, Ozer C, Yildiz A, Apaydin FD, Ozgür A: Antrolithiasis: a retrospective study. J Laryngol Otol. 2003, 117:637-640. 10.1258/002221503768199997

17. Lana JP, Carneiro PM, Machado Vde C, de Souza PE, Manzi FR, Horta MC: Anatomic variations and lesions of the maxillary sinus detected in cone beam computed tomography for dental implants. Clin Oral Implants Res. 2012, 23:1398-1403. 10.1111/j.1600-0501.2011.02321.x

18. Rege IC, Sousa TO, Leles CR, Mendonça EF: Occurrence of maxillary sinus abnormalities detected by cone beam CT in asymptomatic patients. BMC Oral Health. 2012, 12:30. 10.1186/1472-6831-12-30

19. White SC: Cone-beam imaging in dentistry. Health Phys. 2008, 95:628-637. 10.1097/01.HP.0000326340.81581.1a 